www.jmscr.igmpublication.org

Impact Factor (SJIF): 6.379

Index Copernicus Value: 71.58

ISSN (e)-2347-176x ISSN (p) 2455-0450

crossref DOI: _https://dx.doi.org/10.18535/jmscr/v6i3.148

Journal Of Medical Science And Clinical Research

\title{
A Comparative Study between Conventional Dose of Hyperbaric Bupivacaine Alone \& a Combination of lower Fose of Hyperbaric Bupivacaine with Fentanyl for Subarachnoid Block in Turp Surgery among Elederly
}

\author{
Authors \\ Dr Brejesh Ravi Varma ${ }^{1}$, Dr Sreekumar.M ${ }^{2}$ \\ ${ }^{1}$ Asst, Professor, Dept of Anaesthesiology, MES Medical College, Palachode, P.O, Perintalmanna., \\ Pin-679338 India \\ Mobile No.9447991563, Email: brejeshvarma@rediffmail.com \\ ${ }^{2}$ Asst. Professor, Dept of Anaesthesiology, Government Medical College, Palakkad. 678001, India \\ $\mathrm{Ph}$-9847637771, 9447637771, Email: drithva@gmail.com
}

\section{Introduction}

It is universally agreed that the anaesthesia of choice for TURP is a sub arachnoid block and a sensory level of $\mathrm{T}-10$ is recommended to provide excellent anaesthesia and acceptable condition for the patient ${ }^{1}$. Subarachnoid block has always got its own inherent complications, especially related to cardiovascular stability ${ }^{1}$. With limited reflex mediated ability to increase heart rate, hypotension can be frequent and severe peri operatively in elderly ${ }^{3}$.

\section{Design}

It was a prospective study where 60 selected patients who were posted for TURP were randomly divided into 1) Fentanyl (study) group and 2) The Bupivacaine (control) group of 30 patients and compared.

Patients satisfying criteria were randomly divided into two groups each as per random number chart. Both the patient and the principal investigator were blinded to the drug, which was being administered during the period of observation.

\section{Inclusion Criteria}

ASA 1 or 2

Age 65 years and above

Height -155-175 cms

\section{Exclusion Criteria}

History of allergy to local anaesthetics

Patients with spinal deformities, peripheral neuropathy, bleeding disorders or anticoagulation therapy

Patients with serious systemic illness, psychiatric illness, mental retardation.

Patients with Diabetes mellitus, systemic hypertension and ischaemic heart disease.

The patients who were selected and posted for TURP were scrutinised and first sixty subjects were selected for our study as per criteria mentioned above. They were randomly divided into Fentanyl (study) group \& Bupivacaine (control) group using the random number chart

\section{Materials}

26 G Quincke's Needle

$.5 \%$ hyperbaric bupivacaine

Fentanyl as $50 \mathrm{mcg} / \mathrm{ml}$ preservative free solution 


\section{Monitors}

Non invasive Blood pressure monitoring

Pulse oximeter

ECG

Visual assessment of respiration

Finger on pulse

\section{Interventions}

All patients were given oral Ranitidine $150 \mathrm{mg}$ plus Metoclopramide $10 \mathrm{mg}$ plus Alprazolam .25 $\mathrm{mg}$ on the morning of surgery. Psychological preparation was done and procedure explained to all patients in advance

On the table - An Intravenous access was secured using $18 \mathrm{G}$ cannula on the L Fore arm vein and isotonic saline drip was started at a rate of 8 $\mathrm{ml} / \mathrm{kg} / \mathrm{hr}$. No preloading was done. Monitors with pulse oximetry, BP and ECG were used. Midazolam was titrated and given with maximum up to $.025 \mathrm{mg} / \mathrm{kg}$. The patient was kept in left lateral position for sub arachnoid block. Lumbar puncture was done either with the midline or paramedian approach in L3-4 or 2-3 space. After clear CSF was flowing freely, $2 \mathrm{cc}$ of either of the drug (test or control) was injected. The table was kept horizontal throughout. The patient was turned supine immediately. He was kept like that for 7 minutes before he was positioned to lithotomy. Throughout the procedure he was receiving oxygen supplementation of 4 litres /minute via a simple oxygen mask.

\section{Main Outcome and Measures}

The following parameters were assessed and compared

Time for adequate level of analgesia - level T10 assessed by pin prick

Peak sensory level reached during the procedure assessed with pin prick

Time for motor block to recede to level L3/4 (Grade 1 Bromage motor scale)

Duration of analgesia in terms of time for onset of mild pain post operatively as reported by the patient
Incidence of complications including - respiratory depression, hypotension, bradycardia, nausea and vomiting, pruritus, sedation, shivering.

\section{Data Collection}

The principal investigator himself collected the data. Pulse rate and blood pressure were checked every minute for first 20 minutes and every two minutes for next 20 minutes and every five minutes till the end of surgery and then every 10 15 minutes for 3 hours post operatively. They were followed up for 24 hours thereafter with routine post operative care in post surgical wards

Complications during surgery were treated as follows

Hypotension defined as systolic blood pressure of $<90 \mathrm{~mm} \mathrm{Hg}$ or fall of $30 \%$ or more of initial reading, whichever is higher and was treated with $3 \mathrm{mg}$ increments of IV ephedrine

Bradycardia was defined as heart rate less than 50 bpm and was treated with IV Atropine if it was associated with hypotension.

Those subjects who developed TURP syndrome later were noted and excluded from the analysis.

The motor block was assessed using a modified Bromage motor scale

0 - No paresis - full movement of lower limb

1 - Partial paresis - ability to flex knee and angle

2 - Partial paresis - ability to flex foot only

3 - Partial paresis - ability to flex toes only

4 - Full paresis - no movement

\section{Sedation status were assessed as}

0 - None (awake and alert)

1 - Mild - May be sleepy but arousable

2 - Frequently drowsy, but still fully arousable

3 - Severe - Difficult to arouse

$\mathrm{S}-$ Sleeping 


\section{Observations}

\begin{tabular}{|l|c|c|c|c|}
\hline Parametres & $\begin{array}{c}\text { Group 1(Test Group) } \\
\text { Fentanyl }\end{array}$ & $\begin{array}{c}\text { Group 2 (Controll Group) } \\
\text { Bupivacaine }\end{array}$ & P Value & Comments \\
\hline Agy E $($ Years) & $74+\_5.2$ & $73.8+\_5.4$ & .837 & Not Significant \\
\hline Height $(\mathrm{Cm})$ & $166+44.8$ & $165.1+\_12.5$ & .5227 & Not Significant \\
\hline $\begin{array}{l}\text { Duration Of Surgery } \\
\text { (Minutes) }\end{array}$ & $55.3+\_10.4$ & $57.1+\_9.6$ & .4906 & Not Significant \\
\hline
\end{tabular}

\section{Peak Sensory Level of Block}

The peak sensory level of block attained was notably lower in the case of fentanyl group. 21 among 30 patients studied had a peak sensory level at or below $\mathrm{T} 9$, while 25 subjects out of total 27 had a peak sensory level above T9.

\section{Comparison of peak sensory level of block}

\begin{tabular}{|c|c|c|}
\hline $\begin{array}{c}\text { FENTANYL } \\
\text { GROUP }\end{array}$ & $\begin{array}{c}\text { PEAK SENSORY } \\
\text { LEVEL OF BLOCK }\end{array}$ & $\begin{array}{c}\text { BUPIVACAINE } \\
\text { GROUP }\end{array}$ \\
\hline 0 & T-5 & 2 \\
\hline 0 & T-6 & 6 \\
\hline 2 & T-7 & 13 \\
\hline 4 & T- 8 & 4 \\
\hline 15 & T-9 & 2 \\
\hline 6 & T-10 & 0 \\
\hline
\end{tabular}

\section{Cardiovascular Side Effects}

Only two patients among Fentanyl group had episodes of hypotension that required vasopressors where as among Bupivacaine group 15 patients had this in the first 30 minutes after administering the subarachnoid block. Moreover 9 patients among the Bupivacaine group had persistence of hypotension that required more than two boluses of vasopressor, while none among the Fentanyl group required. While maximum fall from the preoperative value among the Fentanyl group was $28.7+\_11.1 \mathrm{~mm} \mathrm{Hg}$, it was $45.5+\_17.2$ $\mathrm{mm} \mathrm{Hg}$, much greater fall in the Bupivacaine group.

There were two patients from each group who had an episode of bradycardia. So there was no statistically significant difference among the groups.

\section{Comparision of Cardiovascular Side Effects}

\begin{tabular}{|l|c|c|c|c|c|}
\hline Measurement & Fentanyl Group & Fentanyl Group & $\begin{array}{c}\text { Bupivacaine } \\
\text { Group }\end{array}$ & $\begin{array}{c}\text { Bupivacaine } \\
\text { Group }\end{array}$ & Comments \\
\hline & $\mathrm{N}-1$ & $\%$ & $\mathrm{~N}-2$ & $\%$ & \\
\hline $\begin{array}{l}\text { Hypotension } \\
\text { (No.Of Persons) }\end{array}$ & 2 & 74 & 15 & 55.5 & $\begin{array}{c}\text { Clinically } \\
\text { Significant }\end{array}$ \\
\hline $\begin{array}{l}\text { Persistant Hypotension } \\
\text { (No.Of Persons) }\end{array}$ & 0 & 0 & 9 & 33.3 & $\begin{array}{c}\text { Clinically } \\
\text { Significant }\end{array}$ \\
\hline $\begin{array}{l}\text { Bradycardia } \\
\text { (No.Of Persons) }\end{array}$ & 2 & 7.4 & 2 & 7.4 & $\begin{array}{c}\text { Clinically } \\
\text { Significant }\end{array}$ \\
\hline
\end{tabular}

\section{Comparision of Maximum BP Fall}

\begin{tabular}{|l|l|l|l|l|}
\hline & $\begin{array}{l}\text { Fentanyl } \\
\text { group }\end{array}$ & Bupivacaine group & P value & Comments \\
\hline Maximum BP Fall & $28.7+\_11.1$ & $45.5+\_17.2$ & $<0.0003$ & Significant \\
\hline
\end{tabular}

\section{Time Parametrs}

The time of onset of adequate level of sensory block was longer among Fentanyl group while they had lower peak of sensory level of block. Fentanyl group had their motor block returned back to normal considerably earlier than those among Bupivacaine group, while both group demonstrated comparable degree of post op analgesia in terms of time of onset and the experience that it pains. 
Comparision of time Measurements

\begin{tabular}{|l|c|c|c|c|}
\hline MEASUREMENT & Fentanyl group & Bupivacaine group & P value & Comments \\
\hline $\begin{array}{l}\text { Time of onset of adequate block } \\
\text { T10( in seconds) }\end{array}$ & $181.5+\_33.2$ & $80.7+\_20.6$ & $<0.0001$ & Significant \\
\hline $\begin{array}{l}\text { Time of recession of motor block } \\
\text { T10( in minutes) }\end{array}$ & $152.2+\_45$ & $233.7+\_44.6$ & $<0.0001$ & Significant \\
\hline Time for onset of pain & $270.37+\_77.5$ & $265.6+\_65.7$ & 0.81 & Not Significant \\
\hline
\end{tabular}

\section{Other side effects}

No subjects in either group had any incidence of sedation or respiratory depression. 2 subjects from each group had intra operative nausea and vomiting. The incidence of shivering was higher among the Bupivacaine group, with 9 subjects experienced shivering while only 2 subjects among the Fentanyl group had it. Another significant finding among the Fentanyl group was the incidence of pruritus (11/30). It never occurred in the Bupivacaine group. Even though urinary retention was a known complication of spinal anaesthesia, we could not compare due to the presence of indwelling bladder catheter.

\section{Other side effects}

\begin{tabular}{|l|c|c|c|c|c|}
\hline & Fentanyl group & & Bupivacaine group & & Comments \\
\hline & $\mathrm{n}-1$ & $\%$ & $\mathrm{n}-2$ & $\%$ & \\
\hline Nausea and vomiting & 2 & 7.4 & 2 & 7.4 & Not Significant \\
\hline Shivering & 2 & 7.4 & 9 & 33.3 & Significant \\
\hline & 11 & 40.7 & 0 & 0 & Significant \\
\hline
\end{tabular}

\section{Discussion}

Maintenance of body physiology as near normal is one of the primary goals of an Anaesthesiologist. As we know marked haemo dynamic derangements occur during subarachnoid blocks, especially in elderly patients ${ }^{5}$. Neuraxial opiods are not associated with sympathetic blocks, skeletal muscle weakness or loss of proprioception. They predominantly act through substantia gelatinosa of spinal cord to extend its synergistic analgesic effect more significantly for visceral pain.

Anaesthetic requirements for TURP patients

The recommended level of analgesia for TURP surgery is T10 as it involves the structures of urethra (S2-4), Prostate (T10 to L2) and bladder $(\mathrm{T} 11)^{2}$. The standard recommended dose of for this is Hyper baric bupivacaine $.5 \% 2 \mathrm{cc}$ or 10 $\mathrm{mg}^{1}$.

In a pilot study done by us earlier, it was found that 1.6 or $1.7 \mathrm{c}$ of Hyperbaric Bupivacaine was sufficient to produce the desired block when given alone.

In our present study, we have added fentanyl a highly lipophilic opioid (.4 cc=20 mcg) to a lower dose of hyperbaric bupivacaine $.5 \% \quad 1.6 \mathrm{cc}$ and compared hemodynamic parameters, duration of analgesia and sensory and motor profiles. With this study both groups were comparable with regarding the age height weight physical status and duration of surgery.

\section{Cardiovascular stability}

Te prime objective of this study was to compare the cardiovascular stability with this drug combination. In our study 15 out of 30 patients among Bupivacaine group developed hypotension while only 2 subjects among the Fentanyl group had the same problem. More over among the 15 in Bupivacaine group 9 developed persistence of hypotension. It is well known that intrathecal opioid specifically exert its synergistic effect (sensory block) without producing motor /sympathetic block. Our study also revealed that degree of BP fall among Bupivacaine group was higher than fentanyl group. These findings are in agreement with findings of Ben David et al (2000), ${ }^{(4)}$ and Matyr et al $(2001)^{(5)}$ who did similar studies among elderly subjects undergoing hip /femur surgeries. 


\section{Time parameters}

There was statistically significant increase in the time of onset of adequate block among the fentanyl group 181+_33 secs when compared to the Bupivacaine group $80.7+20.5$ secs. Time for onset of adequate block However significance of this observation in an elective surgery like TURP may be negligible.

Commercial preparation of Fentanyl citrate is acidic with a $\mathrm{PH}$ of about 4 . During our pilot study we found that addition of $.4 \mathrm{cc}$ fentanyl to $1.6 \mathrm{cc}$ of hyperbaric bupivacaine $.5 \%$ reduced the $\mathrm{Ph}$ of the solution to 5,5 This could be the reason for an observed delay in the onset of adequate block.

\section{Duration of effective analgesia}

There was no statistically difference in post operative analgesia in both groups. 270.4+_77.5 minutes in fentanyl group and 265.5 +_65.7 minutes in bupivacaine group. TURP is not a surgery with considerable post operative pain and so we did not try to quantify pain. The primary concept of pain management is to believe the patient when he says that it's paining. Boucher et $\mathrm{al}^{(6)}$ had obtained similar results with sub arachnoid block with procaine. Bit even more relevant findings may of Obara et al ${ }^{(7)}$ and Goel et al $^{(8)}$ that intrathecal Fentanyl improved the quality and reliability of sub arachnoid block. It could be short acting, but potent analgesic action produces such effect.

\section{Duration of motor block}

Post operative period id usually associated with less ambulance and there for stagnation of blood is more. This increases the risk of venous thromboembolism. The risk is even higher among the elderly. One significant and interesting finding we got was lesser duration of motor blockade mong fentanyl 1 group 152.2+_45 as compared to $233.7+44.6$ in Bupivacaine group.

\section{The peak sensory level of blockade}

Peak sensory level of block as assessed by pin prick was significantly lower among the fentanyl group when compared to bupivacaine group. This finding is similar to Tsung-Ying Chen et al ${ }^{(9)}$ who did a similar study among TURP patients. It's known that the total dose of intrathecal determines the height of block ${ }^{(3)}$. We used a lower dose of Bupivacaine which could explain it. The added fentanyl provided the supplementary visceral analgesia that was required.

Another significant factor that could determine the level of block is the baricity of the drug used intrathecally. ${ }^{(3)}$ Could addition of Fentanyl make the solution hypobaric? So during our pilot study we several samples of both study drug and control drug to test for their specific gravity. It was found that the baricity of commercially available hyperbaric bupivacaine did not significantly change by adding small amount of fentanyl and the solution remained hyperbaric.

\section{Other side effects}

\section{Sedation and respiratory depression}

There was no incidence of sedation or respiratory depression among the subjects in either group. Fentanyl i s very potent yet a relatively short acting opioid when compared to Morphine. It is lipophilic and rapidly absorbed into the spinal cord and epidural fat. This decreases the concentration in CSF rapidly and hence the risk of cephaloid spread is reduced. It has also been found that vascular absorption after intrathecal administration of opioid is clinically insignificant $^{7}$. This could explain the reduced incidence of respiratory depression.

\section{Shivering}

Two among the Fentanyl group and 9 among the bupivacaine group had shivering and it was clinically significant finding. Similar studies have reported by Chow et $\mathrm{al}^{(10)}$. It $\mathrm{s}$ thought that Fentanyl abolishes the shivering by central mechanisms. Though high shivering can be considered as a body's mechanism to prevent hypothermia which is much commoner in TURP patients, it has significant bad effects also. It can increase oxygen consumption which has unwanted consequences in an elderly who may have poor cardiac reserve. 


\section{Pruritus}

The incidence of pruritus especially confined to upper trunk and face has been significantly higher in fentanyl group - 11 persons. Bupivacaine alone did not produce any pruritus. Infact pruritus is considered as the most common side effect of intrathecal opiods. Mulroy et al ${ }^{(11}$ ) has noted a reduced incidence of pruritus when fentanyl is combined with bupivacaine than when combined with lignocaine. Pruritus is thought to be mediated through the meu receptors present centrally (12). Workers have found Ondansetron to be highly useful for treatment of this (13).

\section{Nausea and vomiting}

The incidence of nausea and vomiting was less among both groups. This was unexpected as parenteral opioids like fentanyl is associated with increased of nausea and vomiting. But Copper et al (14) has reported a statistically significant reduction in intraoperative nausea and vomiting. Again Mannulang et $\mathrm{al}^{(15)}$ in a double blinded randomized study has reported that intrathecal Fentanyl is superior to ondansetron for prevention of per operative nausea and vomiting during caesarean section under spinal anaesthesia. Again Ouyang et al ${ }^{(16)}$ in a randomised controlled trail has shown that intrathecal fentanyl can decrease intraoperative vomiting during caesarean sections performed under spinal anaesthesia.

\section{Other reported advantages}

Korhonem et al ${ }^{(17)}$ has noted that PACU time is shorter with intrathecal fentanyl in outpatient surgery. This is significant when compared to morphine which cannot be used for outpatient procedures - Gurkhany et al ${ }^{(18)}$ due to its prolonged action and side effects.

\section{Limitations of this study}

Apart from the possibility of any bias, the most important limitation of this study was that we excluded those subjects who could potentially benefit the most, namely hypertensive, the diabetics and ischaemic heart disease patients. They are candidates who could present with much profound fall in blood pressure. In fact we include them in our pilot study and the results were encouraging.

Yet another limitation was the type of surgery. TURP is well known to be associated with significant fluid absorption, which can produce significant but unpredictable volume changes in the intravascular compartment and thus blood pressure measurement. But this is inevitable and we assumed that if it has affected our observations it has done so in both groups si a similar way only.

\section{Conclusion}

After analysing the results of this study, we find addition of $20 \mathrm{mcg}$ Fentanyl to $1.6 \mathrm{cc}$ of Bupivacaine $.5 \%$ heavy associated with lesser cardiovascular and lesser motor blockade without losing the analgesic efficacy. There was a delay in the onset of action. Also the incidence of pruritus was higher.

Therefore we conclude that subarachnoid block with added fentanyl is a safer option for elderly patients undergoing TURP.

\section{Bibliography}

1. Robert.K.Stoelting(ed) -Neuraxial opioids - p 79-82 in pharmacology \& physiology in Anaesthetic practise, 3 rd edition, 1999, Lippincott Raven

2. Taragho EA, Anatomy of lower urinary tract in Campbell's urology : Walsh et al (eds) 1998, W B Saunders

3. Bertil Lofsrom \& Mats Bengtsson Intradural \& Extradural analgesia in Grey \& Nunn's General Anaesthesia, 5 th edition, Uttang et al (eds)

4. Minidose bupivacaine-fentanyl spinal anesthesia for surgical repair of hip fracture in the aged.Ben-David B et al

5. Martyr JW, Clark MX et al Hypotension in elderly patients undergoing spinal anaesthesia for repair of fractured neck of femur. A comparison of two different spinal solutions. Intrathecal fentanyl does not modify the duration of spinal procaine 
block. Boucher C et al - Can J

Anaesth. 2001 May;48(5):466-9

6. Obara $\mathrm{M}$ et al The effect of intrathecal fentanyl added to hyperbaric bupivacaine for caesarean section

7. Goel $\mathrm{S}^{1}$, et al Intrathecal fentanyl added to intrathecal bupivacaine for day case surgery: a randomized study. Eur J Anaesthesiol. 2003 Apr;20(4):294-7

8. Chen, Tsung-Ying MD; et al The Clinical Use of Small-Dose Tetracaine Spinal Anesthesia for Transurethral Prostatectomy Anesthesia \& Analgesia: April 2001 - Volume 92 - Issue 4 - p 1020-1023

9. Chow TC Et al The influence of small dose intrathecal fentanyl on shivering during transurethral resection of prostate under spinal anesthesia Acta Anaesthesiol Sin. 1994 Sep;32(3):165-70.

10. Mulroy $\mathrm{MF}^{1}$ et al Intrathecal fentanylinduced pruritus is more severe in combination with procaine than with lidocaine or bupivacaine. Reg Anesth Pain Med. 2001 May-Jun;26(3):252-6.

11. Song, Ko MC et al The role of central mu opioid receptors in opioid-induced itch in primates J Pharmacol Exp Ther. 2004 Jul;310(1):169-76. Epub 2004 Mar 25.

12. D. W. COOPER, S. L. LINDSAY et al Does intrathecal fentanyl produce acute cross-tolerance to i.v. morphine? British Journal of Anaesthesia 1997; 78: 311-313

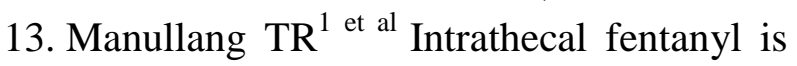
superior to intravenous ondansetron for the prevention of perioperative nausea during cesarean delivery with spinal anesthesia., Anesth Analg. 2000 May;90(5):1162-6.

14. Ouyang MW, et al Inhibiting effect of intrathecal fentanyl on intraoperative vomiting during cesarean delivery under epidural anesthesia

15. Korhonen $\mathrm{AM}^{1}$ Intrathecal hyperbaric bupivacaine $3 \mathrm{mg}+$ fentanyl 10 microg for outpatient knee arthroscopy with tourniquet. Acta Anaesthesiol Scand.2003 Mar;47(3): 342-6

16. Gurkany, Ozdamar et al, Morphine can not be used in outpatient procedures like arthroscopic surgery. Acta. Anaesthesiol. Scand.2004 ; April :48 513-7. 